\title{
Темплатный метод синтеза монодисперсных наночастиц $\mathrm{MoS}_{2}$
}

\author{
() Е.Ю. Стовпяга, Д.А. Курдюков, Д.А. Кириленко, А.Н. Смирнов, А.В. Швидченко, \\ М.А. Яговкина, В.Г. Голубев
}

Физико-технический институт им. А.Ф. Иофрфе Российской академии наук, 194021 Санкт-Петербург, Россия

E-mail: kattrof@gvg.ioffe.ru

Поступила в Редакцию 11 января 2021 г.

В окончательной редакции 18 января 2021 г.

Принята к публикации 18 января 2021 г.

\begin{abstract}
Получены монодисперсные наночастицы дисульфида молибдена в мезопорах темплата - сферических частицах кремнезема $\left(\mathrm{mSiO}_{2}\right)$. Раствор прекурсора - тетратиомолибдата аммония вводился в поры частиц методом капиллярной пропитки. Затем из прекурсора в порах $m \mathrm{SiO}_{2}$ синтезирован $\mathrm{MoS}_{2}$ посредством отжига частиц в атмосфере $\mathrm{H}_{2} \mathrm{~S} / \mathrm{H}_{2}$ в термодинамически равновесных условиях. Для получения индивидуальных наночастиц $\mathrm{MoS}_{2}$ материал темплата $\left(a-\mathrm{SiO}_{2}\right)$ удалялся из композитных частиц $m \mathrm{SiO}_{2} / \mathrm{MoS}_{2}$ путем травления в HF. Микроскопическими методами определено, что средний размер наночастиц $\mathrm{MoS}_{2}$ составляет 3.5 нм. По данным динамического светорассеяния, наночастицы имеют низкое среднеквадратичное отклонение размеров $(18 \%)$.
\end{abstract}

Ключевые слова: $\mathrm{MoS}_{2}$, мезопористый кремнезем, наночастицы, темплатный синтез.

DOI: $10.21883 /$ FTP.2021.05.50841.9587

\section{1. Введение}

Среди слоистых материалов дисульфид молибдена привлекает особое внимание [1,2], так как, во-первых, слои $\mathrm{MoS}_{2}$ связаны между собой слабо (силами Вандер-Ваальса), и, во-вторых, расстояние между слоями - наибольшее среди подобных структур (например, $d_{002}\left(\mathrm{MoS}_{2}\right)=0.63$ нм, $d_{002}$ (графит $)=0.34$ нм$)$. Монослои $\mathrm{MoS}_{2}$ легко разделяются, что позволяет использовать его порошки в качестве твердых смазок [3]. Физические и химические свойства $\mathrm{MoS}_{2}$ обусловливают его применение в катализе и нефтехимии $[2,4]$. При изготовлении катализаторов разделение на слои повышает дисперсность материла и, вследствие этого, увеличивает его удельную поверхность [5]. Кроме того, двумерный дисульфид молибдена имеет прямую запрещенную зону $\left(E_{g} \sim 1.8\right.$ эВ $)$, в отличие от массивного материала, который является непрямозонным полупроводником [6].

Наночастицы $\mathrm{MoS}_{2}$, состоящие из нескольких монослоев и имеющие латеральные размеры, сопоставимые с толщиной, представляют отдельный интерес [7]. Варьируя размеры наночастиц, можно модифицировать их зонную структуру и управлять люминесцентными свойствами [8]. Наночастицы $\mathrm{MoS}_{2}$ широко используются для создания фотокатализаторов [9] и люминесцентных маркеров для исследований in vitro [10] и in vivo [11]. Для получения наноразмерных форм $\mathrm{MoS}_{2}$ не применим подход „top-down“, включающий различные способы эксфолиации (механические, электрохимические, ультразвуковые [12-14]), так как отделяемые слои имеют большие латеральные размеры (до нескольких микрон [12]). Поэтому для синтеза наночастиц $\mathrm{MoS}_{2}$ разработаны методы „bottom-up“, представляющие собой газофазные [15] или жидкостные [16,17] синтезы с использованием различных прекурсоров $\left(\mathrm{MoO}_{2}\right.$ [15], $\mathrm{MoO}_{3}$ [18], $\left(\mathrm{NH}_{4}\right)_{6} \mathrm{Mo}_{7} \mathrm{O}_{24}$ [16], $\mathrm{Na}_{2} \mathrm{MoO}_{4}$ [17]). Получаемые такими методами наночастицы $\mathrm{MoS}_{2}$, как правило, являются полидисперсными.

Одним из способов получения наночастиц $\mathrm{MoS}_{2}$ является темплатный синтез на основе канальных кремнеземов типа MCM-41 [19] и SBA-15 [20]. Так как в этих темплатах отношение длины канала к его диаметру достигает нескольких сотен [21], условия синтеза целевых веществ в зависимости от месторасположения прекурсоров в порах сильно отличаются, что в свою очередь приводит к различию размеров и свойств формирующихся частиц. Перспективным темплатом для получения монодисперсных наночастиц $\mathrm{MoS}_{2}$ выступают синтезированные нами ранее субмикронные монодисперсные $(\sigma<10 \%)$ сферические мезопористые частицы кремнезема $\left(m \mathrm{SiO}_{2}\right)$ [22-24]. Частицы $m \mathrm{SiO}_{2}$ имеют внутреннюю систему цилиндрических наноканалов диаметром $3.1 \pm 0.2$ нм и длиной $10-15$ нм, объемом до $60 \%$ от объема частицы. Наряду с одинаковыми формой и внешним диаметром частиц $m \mathrm{SiO}_{2}$ наличие в них одинаковых пор позволяет при синтезе целевых веществ достичь идентичности условий протекания реакций внутри каждой частицы. Поэтому применение монодисперсных частиц с монодисперсными мезопорами в качестве темплата обусловливает одинаковый размер формирующихся в них материалов, что обеспечивает идентичный химический состав и физико-химические свойства. На основе темплатов $m \mathrm{SiO}_{2}$ ранее разработаны методы синтеза углеродных наноточек $[25,26]$, наночастиц металлов [27], полупроводниковых материалов [28], нитридов [29] и оксидов [30-32].

В настоящей работе темплатным методом синтезированы монодисперсные наночастицы $\mathrm{MoS}_{2}$. Для полу- 
чения в порах целевого вещества частицы $\mathrm{mSiO}_{2}$ пропитывались в растворе прекурсора, а затем осуществлялся термодинамически равновесный синтез $\mathrm{MoS}_{2}$ в атмосфере $\mathrm{H}_{2} \mathrm{~S} / \mathrm{H}_{2}$. Индивидуальные частицы $\mathrm{MoS}_{2}$ получены методом селективного жидкостного травления композитных частиц $m \mathrm{SiO}_{2} / \mathrm{MoS}_{2}$ в растворе плавиковой кислоты для удаления темплата $-a-\mathrm{SiO}_{2}$. Состав и структура наночастиц исследованы методами рентгеновской дифракции, динамического светорассеяния (ДСР), просвечивающей электронной микроскопии высокого разрешения (ВРПЭМ) и рамановской спектроскопии.

\section{2. Методика эксперимента}

В качестве темплата для получения монодисперсных наночастиц $\mathrm{MoS}_{2}$ в настоящей работе использованы частицы $m \mathrm{SiO}_{2}$ диаметром $490 \mathrm{Hм}$, синтезированные посредством гидролиза тетраэтоксисилана (ТЭОС) в этаноло-водно-аммиачной среде в присутствии структурообразующего вещества цетилтриметиламмоний бромида (ЦТАБ). Мольное соотношение реагентов ТЭОС: $\mathrm{C}_{2} \mathrm{H}_{5} \mathrm{OH}: \mathrm{H}_{2} \mathrm{O}: \mathrm{NH}_{3}$ :ЦТАБ составляло $1: 250: 45: 400: 0.25$ соответственно. Для удаления органических веществ синтезированные частицы отжигались на воздухе при температуре $800 \mathrm{~K}$. Среднеквадратичное отклонение диаметров частиц $\mathrm{mSiO}_{2}$ составило $<6 \%$, диаметр мезопор равен $3.1 \pm 0.2$ нм, объемная доля пор $\sim 50$ об\%, удельная поверхность $-750 \mathrm{~m}^{2} /$ г. Подробно методика синтеза частиц описана в рабо$\operatorname{Tax}[22,23]$.

Для получения $\mathrm{MoS}_{2}$ в стеклянную чашку Петри, содержащую навеску мезопористых частиц $\mathrm{mSiO}_{2}$ массой 0.5 г, вливался $12 \%$-й раствор $\left(\mathrm{NH}_{4}\right)_{2} \mathrm{MoS}_{4}$ (Aldrich) в диметилформамиде (ДМФ) объемом 2 мл. Частицы $m \mathrm{SiO}_{2}$ находились в контакте с раствором в течение 72 ч. Затем частицы высушивались при температуре $350 \mathrm{~K}$ и отжигались на воздухе при $430 \mathrm{~K}$ для удаления ДМФ. Последующий отжиг $\mathrm{mSiO}_{2}$ частиц, заполненных $\left(\mathrm{NH}_{4}\right)_{2} \mathrm{MoS}_{4}$, проводили в термодинамически равновесных условиях. Образцы помещались в кварцевый реактор, через который пропускали смесь $\mathrm{H}_{2} \mathrm{~S} / \mathrm{H}_{2}$ под общим давлением 1 бар. Парциальное давление $\mathrm{H}_{2} \mathrm{~S}$ составляло 0.9 бар, $\mathrm{H}_{2}-0.1$ бар. Синтез проводили при температуре $680 \mathrm{~K}$ в течение 20 ч.

Для травления темплата $\left(a-\mathrm{SiO}_{2}\right)$ навеску композитных частиц $m \mathrm{SiO}_{2} / \mathrm{MoS}_{2}$ помещали в 20 г $1 \%$-го $\mathrm{HF}$. После растворения $\mathrm{SiO}_{2}$ наночастицы $\mathrm{MoS}_{2}$ отделяли центрифугированием. Затем осадок наночастиц $\mathrm{MoS}_{2}$ трижды промывался деионизованной водой.

Измерение размера и электрофоретической подвижности синтезированных монодисперсных наночастиц $\mathrm{MoS}_{2}$ определяли методом ДСР на анализаторе Malvern Zetasizer Nano ZS при температуре $25^{\circ} \mathrm{C}$. Расчет распределения гидродинамических диаметров и электрокинетического потенциала осуществлялся с помощью встроенного программного обеспечения анализатора.
Исследования микроструктуры наночастиц $\mathrm{MoS}_{2}$ проводились на просвечивающем электронном микроскопе Jeol JEM-2100F. Фазовый состав определялся рентгенодифракционным методом на установке D2 Phaser, Bruker, Германия ( $\mathrm{Cu} K_{\alpha}$-излучение). Рамановские спектры измерялись при комнатной температуре на спектрометре Horiba Jobin Yvon T64000 с использованием в качестве источника излучения второй гармоники $\mathrm{Nd}$ : YAG-лазера $(\lambda=532$ нм $)$, плотность возбуждения на поверхности образца не превышала $P=2$ кВт/см².

\section{3. Результаты и обсуждение}

Рассмотрим подробно процессы, протекающие в порах частиц $m \mathrm{SiO}_{2}$ при синтезе $\mathrm{MoS}_{2}$. На первом этапе осуществлялась пропитка $m \mathrm{SiO}_{2}$ прекурсором - раствором $\left(\mathrm{NH}_{4}\right)_{2} \mathrm{MoS}_{4}$ в ДМФ. В ходе длительного контакта мезопористых частиц кремнезема с раствором прекурсора последний практически полностью переходил в поры частиц благодаря их высокой адсорбционной способности $[22,25,33,34]$. Далее при высушивании происходила кристаллизация прекурсора в порах частиц. На втором этапе стояла задача синтеза $\mathrm{MoS}_{2}$ из прекурсора непосредственно в порах темплата.

Существует разнообразие соединений молибдена с различными степенями окисления атомов Мо, что сильно усложняет задачу получения целевого однофазного вещества - $\mathrm{MoS}_{2}$. В настоящей работе $\mathrm{MoS}_{2}$ был синтезирован из прекурсора $\left(\mathrm{NH}_{4}\right)_{2} \mathrm{MoS}_{4}$ в термодинамически равновесных условиях, обеспечивающих образование только сульфида Мо (IV). Для определения параметров процесса восстановления (температуры и парциальных давлений $\mathrm{H}_{2}$ и $\mathrm{H}_{2} \mathrm{~S}$ ) был выполнен расчет равновесного состава смеси в системе $\mathrm{MoS}_{3}$, $\mathrm{Mo}_{2} \mathrm{~S}_{5}, \mathrm{MoS}_{2}, \mathrm{Mo}_{2} \mathrm{~S}_{3}, \mathrm{Mo}_{6} \mathrm{~S}_{8}, \mathrm{Mo}_{7} \mathrm{~S}_{8}, \mathrm{MoS}, \mathrm{MoO}_{3}, \mathrm{MoO}_{2}$, Mo, $\mathrm{H}_{2}(g), \mathrm{H}_{2} \mathrm{O}(g), \quad \mathrm{NH}_{3}(g), \mathrm{S}_{8}(g), \mathrm{S}_{4}(g), \mathrm{S}_{2}(g)$ и $\mathrm{H}_{2} \mathrm{~S}(\mathrm{~g})$. Расчет проводился с использованием алгоритма Villars-Cruise-Smith [35]. Значения стандартных химических потенциалов были взяты из базы данных IVTANTERMO [36], химические потенциалы газофазных компонентов рассчитаны в приближении идеально ассоциированного газа. Расчет показал, что при парциальном давлении водорода $P_{\mathrm{H} 2}=0.1$ бар, сероводорода $P_{\mathrm{H} 2 \mathrm{~S}}=0.9$ бар, общем давлении $P=1$ бар в диапазоне температур 650-700 K прекурсор $\left(\mathrm{NH}_{4}\right)_{2} \mathrm{MoS}_{4}$ полностью переходит в $\mathrm{MoS}_{2}$, количество примесей составляет $<0.1$ мол\%. При температурах до $650 \mathrm{~K}$ возможно одновременное образование $\mathrm{MoS}_{3}, \mathrm{Mo}_{2} \mathrm{~S}_{5}$ и $\mathrm{MoS}_{2}$. В температурном интервале 700-1200 K возможно образование $\mathrm{MoS}_{2}, \mathrm{Mo}_{2} \mathrm{~S}_{3}, \mathrm{Mo}_{6} \mathrm{~S}_{8}, \mathrm{Mo}_{7} \mathrm{~S}_{8}, \mathrm{MoS}$ в различных соотношениях, в зависимости от температуры. При температурах $>1200 \mathrm{~K}$ реакция идет до элементарного молибдена. В результате в настоящей работе процесс получения $\mathrm{MoS}_{2}$ проводили при $680 \mathrm{~K}$. Синтез $\mathrm{MoS}_{2}$ из прекурсора $\left(\mathrm{NH}_{4}\right)_{2} \mathrm{MoS}_{4}$ идет посредством реакции: $\left(\mathrm{NH}_{4}\right)_{2} \mathrm{MoS}_{4}+\mathrm{H}_{2} \rightarrow 2 \mathrm{NH}_{3} \uparrow+2 \mathrm{H}_{2} \mathrm{~S} \uparrow+\mathrm{MoS}_{2}$. 


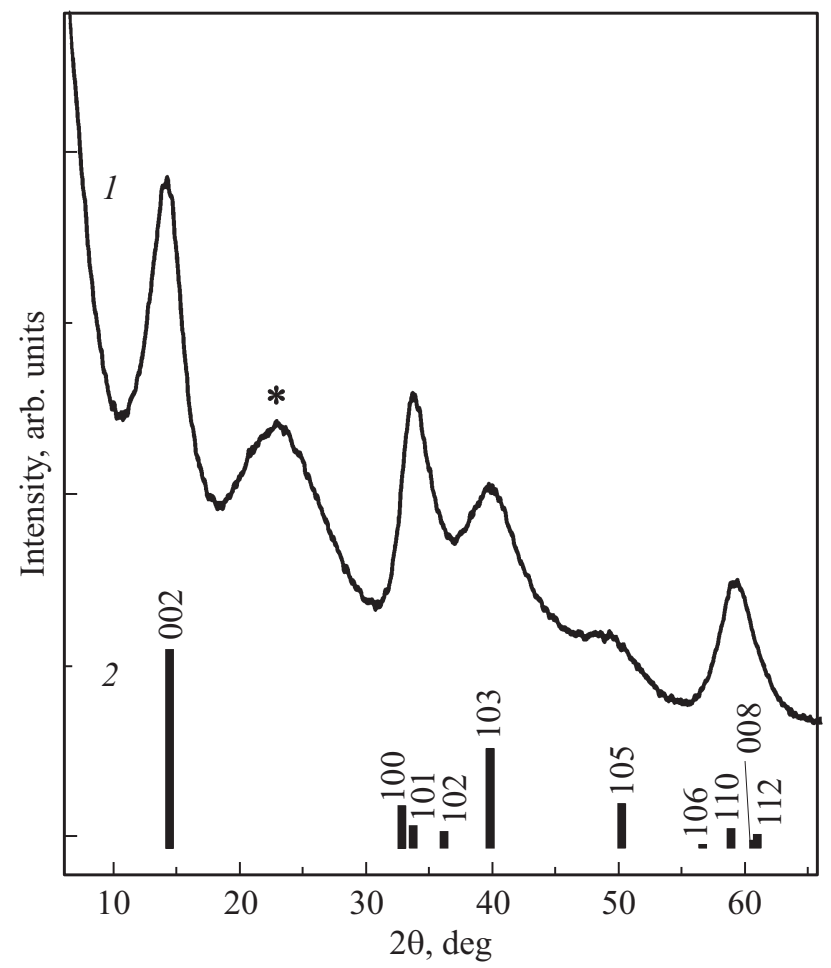

Рис. 1. Дифракционные кривые: 1 - композитные частицы $m \mathrm{SiO}_{2} / \mathrm{MoS}_{2}, 2-2 \mathrm{H}-\mathrm{MoS}_{2}$ (JCPDS 03-065-0160). Звездочкой отмечено диффузное „гало“ аморфного $\mathrm{SiO}_{2}$.

Наличие продукта реакций восстановления - сероводорода в исходной газовой смеси препятствует образованию сульфидов молибдена со степенью окисления атомов Мо, меньшей +4 , согласно принципу Ле Шателье.

Результаты расчета подтверждаются экспериментально. По данным рентгенофазового анализа (рис. 1), на дифракционной кривой полученных композитных частиц $m \mathrm{SiO}_{2} / \mathrm{MoS}_{2}$ наблюдается набор рефлексов, соответствующий $2 \mathrm{H}-\mathrm{MoS}_{2}$ (JCPDS 03-065-0160). На кривой присутствует также широкое „гало“ с максимумом в области $2 \theta \sim 22^{\circ}$, которое обусловлено диффузным отражением от аморфного $\mathrm{SiO}_{2}$ (материала темплата). Дифракционные пики молибденита уширены, что свидетельствует о том, что $\mathrm{MoS}_{2}$ является нанокристаллическим [37]. Рассчитанный по интегральному уширению дифракционных максимумов средний размер области когерентного рассеяния $\mathrm{MoS}_{2}$ составляет 3.5 нм, данное значение коррелирует с диаметром цилиндрических мезопор (3.1 нм) частиц $m \mathrm{SiO}_{2}$. Соотношение интенсивностей рефлексов $\mathrm{MoS}_{2}$ в исследуемом образце существенно отличается от стандартного, наблюдается преимущественная ориентация кристаллитов дисульфида молибдена в направлении [001] (по оси с $\mathrm{MoS}_{2}$ ). Вероятно, синтезированный $\mathrm{MoS}_{2}$ имеет турбостратную структуру, наблюдаемая дифракционная картина является двумерной, дифракционные рефлексы от плоскостей с тремя ненулевыми индексами (112) или нулевым третьим индексом (110) имеют заниженную интенсивность или вовсе отсут- ствуют. Подобная двумерная дифракция проявляется, например, в углеродных наноточках с турбостратной структурой [26].

ВРПЭМ-изображение индивидуальных наночастиц $\mathrm{MoS}_{2}$, полученных посредством селективного травления материала темплата - аморфного $\mathrm{SiO}_{2}$ плавиковой кислотой, представлено на рис. 2. На рисунке видны наночастицы (темные области), имеющие латеральные размеры 3-7 нм и толщину $1.5-4$ нм. На рисунке обозначены характерные межплоскостные расстояния в синтезированных наночастицах $\mathrm{MoS}_{2}\left(d_{002}=0.63\right.$ нм и $d_{100}=0.27$ нм). Наблюдаемые в пределах одной наночастицы две системы кристаллографических плоскостей подтверждают, что частицы состоят из нескольких монослоев $\mathrm{MoS}_{2}$.

На рис. 3 представлен типичный рамановский спектр синтезированных наночастиц $\mathrm{MoS}_{2}$ в области частот $100-500 \mathrm{~cm}^{-1}$. В спектре наблюдаются интенсивные фононные моды $E_{1 g}, E_{2 g}^{1}$ и $A_{1 g}$, характерные для $\mathrm{MoS}_{2}$ [38-41]. Мода $E_{2 g}^{1}\left(\sim 382 \mathrm{~cm}^{-1}\right)$ обусловлена колебаниями атомов $\mathrm{S}-\mathrm{Mo}-\mathrm{S}$ в плоскости одного монослоя, а мода $A_{1 g}\left(\sim 407 \mathrm{~cm}^{-1}\right)$ возникает благодаря колебаниям атомов серы S, перпендикулярным к этим слоям (связи Ван-дер-Ваальса). Положение данных мод зависит от толщины (количества слоев) исследуемых образцов [39]. Смещение положения максимума полос $E_{2 g}^{1}$ в высокочастотную область спектра, а максимума полосы $A_{1 g}-$ в низкочастотную, относительно табличных значений для массивного материала, свидетельствует о том, что синтезированные наночастицы состоят из конечного числа слоев $\mathrm{MoS}_{2}$ [40]. Кроме оптических рамановских мод, в спектре имеются полосы, обусловленные продольной

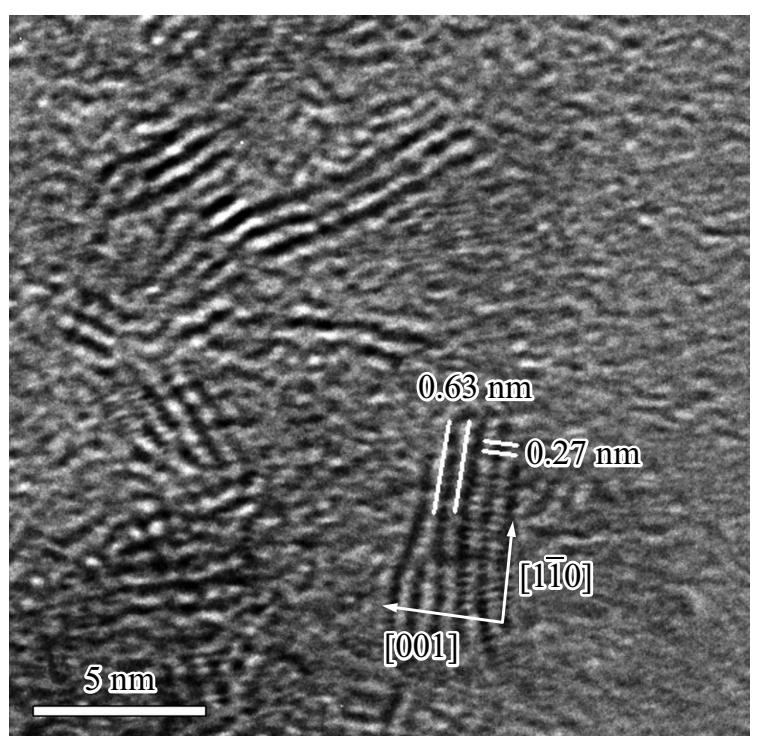

Рис. 2. ВРПЭМ-изображение синтезированных наночастиц. Стрелками показаны направления [001] и [11̄0] в нанокристалле $\mathrm{MoS}_{2}$. На рисунке обозначены характерные межплоскостные расстояния. 


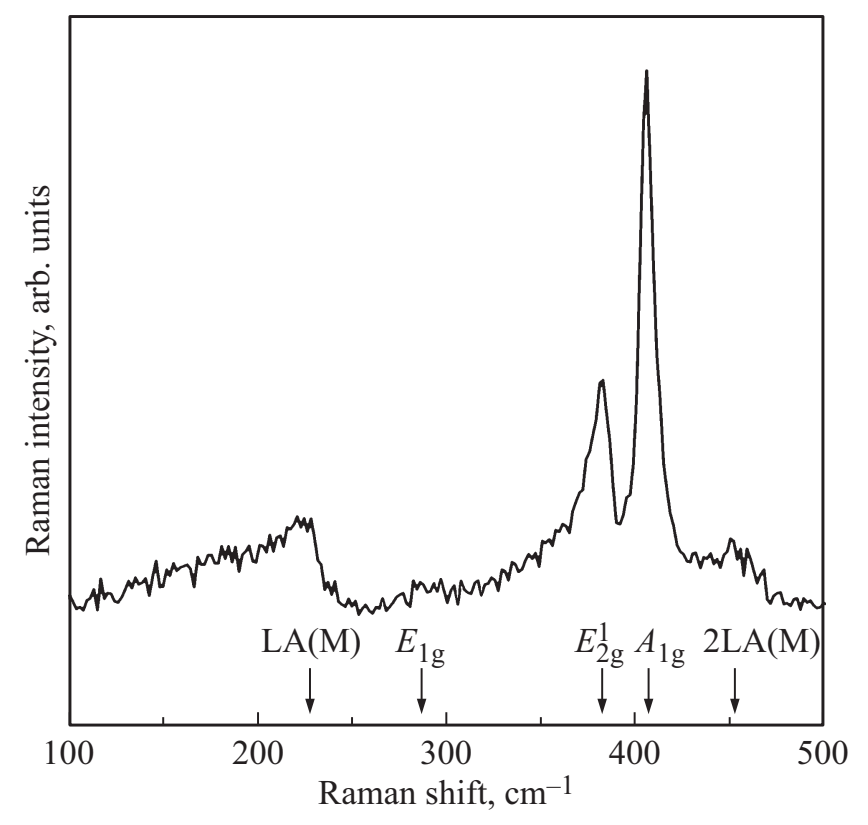

Рис. 3. Рамановский спектр синтезированных наночастиц $\mathrm{MoS}_{2}$. Стрелками обозначены положения раман-активных фононных мод первого порядка объемного $\mathrm{MoS}_{2}$ и индуцированных дефектами полос LA и 2LA.

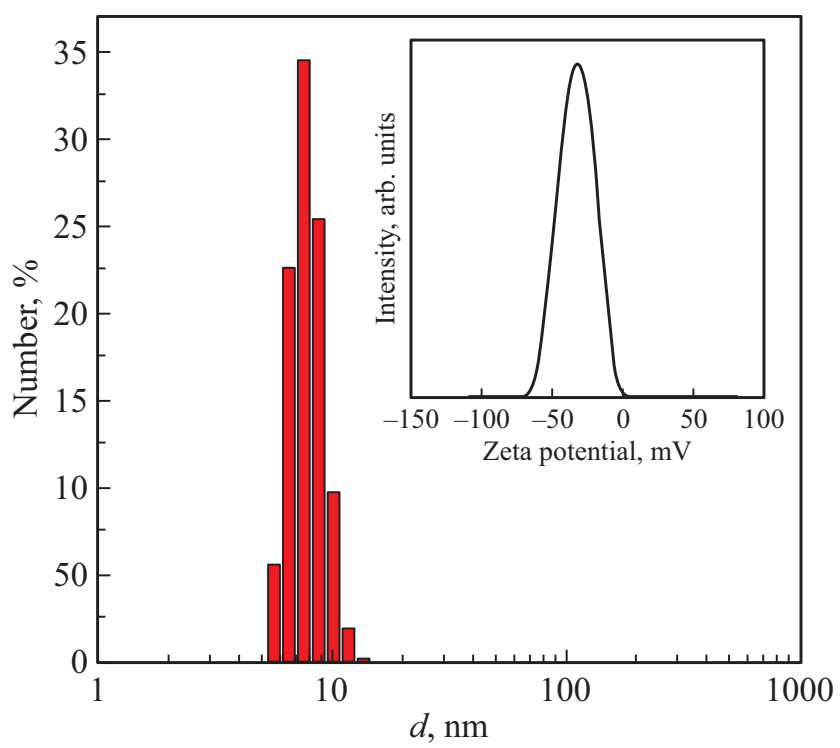

Рис. 4. Распределение гидродинамических диаметров наночастиц $\mathrm{MoS}_{2}$ в воде, измеренное методом ДСР. На вставке электрокинетический потенциал наночастиц $\mathrm{MoS}_{2}$, измеренный при $\mathrm{pH}=8$.

акустической модой $\mathrm{LA}(M)[38,41]$, что свидетельствует о наличии дефектов в структуре наночастиц. Детальному исследованию оптических свойств (поглощения, люминесценции) синтезированных наночастиц $\mathrm{MoS}_{2}$ будет посвящена отдельная публикация.

Средний гидродинамический диаметр синтезированных наночастиц $\mathrm{MoS}_{2}$, по данным ДСР, составил
$7.5 \pm 1.5$ нм (рис. 4). Отличие значения размера частиц, измеренного методом ДСР, от размера, полученного по результатам ВРПЭМ исследований, по-видимому, связано с двумя причинами. Во-первых, с наличием ионной оболочки у частиц в коллоидном растворе, увеличивающей их эффективный размер, во-вторых, с тем, что для расчета гидродинамических диаметров использовались значения оптических констант массивного $\mathrm{MoS}_{2}$. Для наночастиц коэффициент поглощения и показатель преломления могут быть иными. На рис. 4 (см. вставку) приведено распределение электрокинетического потенциала наночастиц $\mathrm{MoS}_{2}$ в дисперсионной среде с $\mathrm{pH}=8$. Наблюдаемый максимум соответствует значению $-34 \mathrm{MB}$, следовательно, коллоидный раствор $\mathrm{MoS}_{2}$ является агрегативно устойчивым. По-видимому, в слабощелочной среде происходит диссоциация тиоловых $(-\mathrm{SH})$ групп по кислотному механизму, в результате поверхность наночастиц $\mathrm{MoS}_{2}$ приобретает отрицательный заряд $\left(-\mathrm{S}^{-}\right)$.

\section{4. Заключение}

Разработан метод синтеза монодисперсных наночастиц $\mathrm{MoS}_{2}$ из прекурсора - тетратиомолибдата аммония с использованием в качестве темплата монодисперсных сферических мезопористых частиц кремнезема. Выполнено термодинамическое моделирование процесса и определены условия (температура и состав исходной газовой смеси), обеспечивающие равновесный синтез однофазного $\mathrm{MoS}_{2}$. Методика включает в себя стадии введения в мезопоры темплата прекурсора, синтеза из него дисульфида молибдена и селективного удаления материала темплата раствором плавиковой кислоты. Методами рентгеновской дифракции и рамановской спектроскопии показано, что синтезированный материал содержит только одну кристаллическую фазу $-2 \mathrm{H}-\mathrm{MoS}_{2}$. Рассчитанный методом Ритвельда средний размер области когерентного рассеяния $\mathrm{MoS}_{2}$ составил $3.5 \mathrm{Hм}$. Методом ВРПЭМ установлено, что синтезированные частицы $\mathrm{MoS}_{2}$ являются нанокристаллическими и состоят из 2-5 монослоев. По результатам ДСР, полученные наночастицы являются монодисперсными, их средний гидродинамический диаметр составляет $7.5 \pm 1.5$ нм.

\section{Финансирование работы}

Работа выполнена при финансовой поддержке РФФИ (грант № 20-03-00656).

\section{Благодарности}

Исследования методом просвечивающей электронной микроскопии и рентгеновской дифракции выполнены с использованием оборудования федерального ЦКП „Материаловедение и диагностика в передовых технологиях“. 


\section{Конфликт интересов}

Авторы заявляют, что у них нет конфликта интересов.

\section{Список литературы}

[1] L. Li, Z. Guo, S. Wang, D. Li, X. Hou, F. Wang, Y. Yang, X. Yang. Anal. Methods, 11, 3307 (2019).

[2] W. Choi, N. Choudhary, G.H. Han, J. Park, D. Akinwande, Y.H. Lee. Materials Today, 20, 116 (2017).

[3] M.R. Vazirisereshk, A. Martini, D.A. Strubbe, M.Z. Baykara. Lubricants, 7, 57 (2019).

[4] A. Molina-Sánchez, K. Hummer, L. Wirtz. Surf. Sci. Reports, 70, 554 (2015).

[5] M. Ahmadi, O. Zabihi, Q. Li, S.M. Fakhrhoseini, M. Naebe. Nanomaterials, 9, 1400 (2019).

[6] A. Splendiani, L. Sun, Y. Zhang, T. Li, J. Kim, C.-Yu. Chim, G. Galli, F. Wang. Nano Lett., 10, 1271 (2010).

[7] N. Wang, F. Wei, Y.H. Qi, H.X. Li, X. Lu, G.Q. Zhao, Q. Xu. ACS Appl. Mater. Interfaces, 6, 19888 (2014).

[8] D. Bhattacharya, S. Mukherjee, R.K. Mitra, S.K. Ray. Nanotechnology, 31, 145701 (2020).

[9] S. Bertolazzi, J. Brivio, A. Kis. ACS Nano, 5, 9703 (2011).

[10] W. Dai, H. Dong, B. Fugetsu, Y. Cao, H.T. Lu, X.L. Ma, X.J. Zhang. Small, 11, 4158 (2015).

[11] J. Wang, X. Tan, X. Pang, L. Liu, F. Tan, N. Li. ACS Appl. Mater. Interfaces, 8, 24331 (2016).

[12] X. Huang, Z. Zeng, H. Zhang. Chem. Soc. Rev., 42, 1934 (2013).

[13] Z. Zeng, T. Sun, J. Zhu, X. Huang, Z. Yin, G. Lu, Z. Fan, Q. Yan, H.H. Hng, H. Zhang. Angew. Chem. Int. Ed., 51, 9052 (2012).

[14] X. Tan, W. Kang, J. Liu, C. Zhang. Nanoscale Res. Lett., 14, 317 (2019).

[15] Q. Li, E.C. Walter, W.E. Van Der Veer, B.J. Murray, J.T. Newberg, E.W. Bohannan, J.A. Switzer, J.C. Hemminger, R.M. Penner. J. Phys. Chem. B, 109, 3169 (2005).

[16] X. Feng, Q. Tang, J. Zhou, J. Fang, P. Ding, L. Sun, L. Shi. Cryst. Res. Technol., 6 (2013) 1-6.

[17] X. Ren, L. Pang, Y. Zhang, X. Ren, H. Fan, S. Liu. J. Mater. Chem. A, 3, 10693 (2015).

[18] S. Balendhran, J.Z. Ou, M. Bhaskaran, S. Sriram, S. Ippolito, Z. Vasic, E. Kats, S. Bhargava, S. Zhuiykov, K. Kalantar-zadeh. Nanoscale, 4, 461 (2012).

[19] Y. Wang, S. Wang, C. Li, M. Qian, J. Bu, J. Wang, R. Huang. Chem. Commun., 52, 10217 (2016).

[20] Z.-D. Huang, W. Bensch, L. Kienle, S. Fuentes, G. Alonso, C. Ornelas. Catal. Lett., 122, 67 (2008).

[21] J.S. Beck, J.C. Vartuli, W.J. Roth, M.E. Leonowicz, C.T. Kresge, K.D. Schmitt, C.T.W. Chu, D.H. Olson, E.W. Sheppar. J. Amer. Chem. Soc., 114, 10834 (1992).

[22] Е.Ю. Трофимова, Д.А. Курдюков, Ю.А. Кукушкина, М.А. Яговкина, В.Г. Голубев. Физика и химия стекла, 37, 38 (2011).

[23] E.Yu. Trofimova, D.A. Kurdyukov, S.A. Yakovlev, D.A. Kirilenko, Yu.A. Kukushkina, A.V. Nashchekin, A.A. Sitnikova, M.A. Yagovkina, V.G. Golubev. Nanotechnology, 24, 155601 (2013).

[24] D.A. Kurdyukov, D.A. Eurov, D.A. Kirilenko, J.A. Kukushkina, V.V. Sokolov, M.A. Yagovkina, V.G. Golubev. Microp. Mesopor. Mater., 223, 225 (2016).
[25] Д.А. Курдюков, Д.А. Еуров, Е.Ю. Стовпяга, Д.А. Кириленко, С.В. Коняхин, А.В. Швидченко, В.Г. Голубев. ФТТ, 58, 2454 (2016).

[26] D.A. Kurdyukov, D.A. Eurov, M.K. Rabchinskii, A.V. Shvidchenko, M.V. Baidakova, D.A. Kirilenko, S.V. Koniakhin, V.V. Shnitov, V.V. Sokolov, P.N. Brunkov, A.T. Dideikin, Ye.M. Sgibnev, L.Yu. Mironov, D.A. Smirnov, A.Ya. Vul', V.G. Golubev. Nanoscale, 10, 13223 (2018).

[27] Д.А. Курдюков, Д.А. Еуров, Е.Ю. Стовпяга, С.А. Яковлев, Д.А. Кириленко, В.Г. Голубев. ФТТ, 56, 995 (2014).

[28] Д.А. Курдюков, Н.А. Феоктистов, Д.А. Кириленко, А.Н. Смирнов, В.Ю. Давыдов, В.Г. Голубев. ФТП, 53, 1068 (2019).

[29] Е.Ю. Стовпяга, Д.А. Еуров, Д.А. Курдюков, А.Н. Смирнов, M.A. Яговкина, D.R. Yakovlev, В.Г. Голубев. ФТП, 52, 1000 (2018).

[30] Е.Ю. Стовпяга, Д.А. Еуров, Д.А. Курдюков, А.Н. Смирнов, М.А. Яговкина, В.Ю. Григорьев, В.В. Романов, D.R. Yakovlev, В.Г. Голубев. ФТT, 59, 1598 (2017).

[31] D.A. Eurov, D.A. Kurdyukov, D.A. Kirilenko, J.A. Kukushkina, A.V. Nashchekin, A.N. Smirnov, V.G. Golubev. J. Nanopart. Res., 17, 82 (2015).

[32] K.N. Orekhova, D.A. Eurov, D.A. Kurdyukov, V.G. Golubev, D.A. Kirilenko, V.A. Kravets, M.V. Zamoryanskaya. J. Alloys Compd., 678, 434 (2016).

[33] Е.Ю. Трофимова, С.А. Грудинкин, Ю.А. Кукушкина, Д.А. Курдюков, А.В. Медведев, М.А. Яговкина, В.Г. Голубев. ФТТ, 54, 1220 (2012).

[34] Д.А. Еуров, С.А. Грудинкин, Д.А. Курдюков, А.В. Медведев, Е.Ю. Стовпяга, В.Г. Голубев. Письма ЖТФ, 41, 19, 1 (2015).

[35] W.R. Smith, R.L. Missen. Chemical Reaction Equilibrium Analisys: Theory and Algorithms (Wiley-VCH, Germany, 1982).

[36] L.V. Gurvich, V.S. Iorish, D.V. Chekhovskoi, V.S. Yungman. IVTANTHERMO - A Thermodynamic Database and Software System for the Personal Computer. User's Guide (CRC Press, Inc. Boca Raton, 1993).

[37] B. Lei, G.R. Li, X.P. Gao. J. Mater. Chem. A, 2, 3919 (2014).

[38] S. Mignuzzi, A.J. Pollard, N. Bonini, B. Brennan, I.S. Gilmore, M.A. Pimenta, D. Richards, D. Roy. Phys. Rev. B, 91, 195411 (2015).

[39] A. Abraham, Lei Wang, C.D. Quilty, D.M. Lutz, A.H. McCarthy, C.R. Tang, M.R. Dunkin, L.M. Housel, E.S. Takeuchi, A.C. Marschilok, K.J. Takeuchi. ChemSusChem, 13, 1517 (2020).

[40] H. Li, Q. Zhang, C.C.R. Yap, B.K. Tay, T.H.T. Edwin, A. Olivier, D. Baillargeat. Adv. Funct. Mater., 22, 1385 (2012).

[41] A. Molina-Sánchez, L. Wirtz. Phys. Rev. B, 84, 155413 (2011).

Редактор А.Н. Смирнов 


\section{Synthesis of monodisperse $\mathrm{MoS}_{2}$ nanoparticles by the template method}

E.Yu. Stovpiaga, D.A. Kurdyukov, D.A. Kirilenko,

A.N. Smirnov, A.V. Shvidchenko, M.A. Yagovkina,

V.G. Golubev

loffe Institute,

194021 St. Petersburg, Russia

Abstract Monodisperse molybdenum disulfide nanoparticles were synthesized in mesopores of spherical silica particles $\left(m \mathrm{SiO}_{2}\right)$ served as a template. First, the pores of $\mathrm{mSiO}_{2}$ particles were impregnated with the precursor (ammonium tetrathiomolybdate solution). Then, the reduction of the filler in thermodynamically equilibrium conditions in $\mathrm{H}_{2} \mathrm{~S} / \mathrm{H}_{2}$ atmosphere was carried out. The template material $\left(a-\mathrm{SiO}_{2}\right)$ was selectively etched from the composite $m \mathrm{SiO}_{2} / \mathrm{MoS}_{2}$ particles with $\mathrm{HF}$ to obtain individual $\mathrm{MoS}_{2}$ nanoparticles. The mean size of $\mathrm{MoS}_{2}$ nanoparticles determined by microscopic methods was found to be $3.5 \mathrm{~nm}$. According to dynamic light scattering data, the nanoparticles had low size scatter $(18 \%)$. 